\title{
COMPARISON OF CHRONOLOGICAL AND CORRECTED AGES IN THE GROSS MOTOR ASSESSMENT OF LOW-RISK PRETERM INFANTS DURING THE FIRST YEAR OF LIFE
}

\author{
Ana Paula Restiffe', José Luiz Dias Gherpelli
}

\begin{abstract}
Objective: To evaluate the need of chronological age correction according to the degree of prematurity, when assessing gross motor development in preterm infants, during the first year of life. Method:Cohort, observational and prospective study. Alberta Infant Motor Scale (AIMS) was used to evaluate 43 preterminfants with low risk for motor neurological sequelae, during the first year of corrected age. Mean scores were analyzed according to chronological and corrected ages. Children with motor neurological sequelae were excluded during follow-up. Results: G ross motor mean scores in preterm infants tended to be higher when corrected age was used compared with those obtained when using chronological age, during the first twelve months. At thirteen months of corrected age, an overlapping of confidence intervals between corrected and chronological ages was observed, suggesting that from that period onwards correction for the degree of prematurity is no longer necessary. Conclusion: Corrected age should be used for gross motor assessment in preterm infants during the first year of life.
\end{abstract}

KEY WORDS: premature infant, low birth-weight infant, gestational age, motor activity.

\begin{abstract}
Comparação das idades cronológica e corrigida na avaliação motora grosseira de lactentes prétermo com baixo risco no primeiro ano de vida

RESUMO - Objetivo: Verificar a necessidade de corrigir a idade cronológica de acordo com o grau de prematuridade, na avaliação do desenvolvimento motor grosseiro em recém-nascidos pré-termo, durante o primeiro ano de vida. Método: Estudo coorte, observacional e prospectivo. A Escala Motora Infantil de Alberta (AIMS) foi usada para avaliar 43 recém-nascidos pré-termos com baixo risco para lesão neuro lógica motora durante o primeiro ano de vida. A média dos escores foi analisada segundo as idades corr i g idas e cronológicas. As crianças com seqüela motora neurológica foram excluídas durante o seguimento. Resultados: A média dos escores do desenvolvimento motor grosseiroquando foi utilizada a idade corrigida tendeu a ser maior do que aqueles obtidos quando se utilizou a idade cronológica, durante os primeiros 12 meses. Aos 13 meses de idade corrigida, foi observada sobreposição dos intervalos de confiança das médias dos escores entre as idades corrigidas e cronológicas, sugerindo que a partir deste período, a correção pelo índice de prematuridade não é mais necessária ao avaliar o desenvolvimento motor grosseiro de lactentes pré-termo. Conclusão: A idade corrigida deve ser usada na avaliação do desenvolvimento motor de recém-nascidos pré-termos durante o primeiro ano de vida.
\end{abstract}

PALAVRAS-CHAVE: lactente pré-termo, lactente de baixo-peso, idade gestacional, atividade motora.

Several pre and perinatal complications seen in preterm infants are well known risk factors for the development of future neurological disabilities. The incidence of major disabilities is inversely related to b i rthweight and gestational age ranging from $20 \%$ to $40 \%$, during the first years of life $\mathrm{e}^{1-3}$. Not only do $s t$ ress and medical complications make the premature births qualitatively diffe rent from full-term births, but also the long period in the incubator and the early influence of gravidity have an impact on preterm postural development at and after term ${ }^{4-6}$. There is still controversy among the studies in the literature whether the neurodevelopment of pre te rmwithout major neurological sequelae are either delayed ${ }^{7-9}$; accelerated $^{10,11}$; or equivalent to term infant development ${ }^{12-16}$. Some authors ${ }^{13,14,16}$ have found that pre-

Department of Neurology, University of São Paulo Medical School, São Paulo SP, Brazil: ${ }^{~}$ Physiotherapist, MSc; ${ }^{2}$ Pediatric Neurologist, PhD.

Received 12 July 2005, received in final form 2 December 2005. Accepted 2 February 2006.

Dra. Ana Paula Restiffe - Rua Lourenço de Almeida 772/ 51 - 04508-001 São Paulo SP - Brasil. E-mail: aprestiffe@sgl.com.br 
maturity may jeopardize gross and fine motor development domains, while others ${ }^{17}$ concluded that the major impact was on the mental skills. Most studies ${ }^{7}$ 9, 13-14,16, 18-21 addressing the developmental outcome of prete minfants have taken into account both chronological and corrected ages. Studies using corre ction point out that such procedu re can overestimate the developmental pro $g$ ress in preterminfants, because most of the infants would be considered to be in the normal or relatively high-average level of development $12-15,17,20,21$. On the other hand, the use of ch ronological age would underestimate the developmental prog ress and there would be a higher rate of preterm infants reported as suspect, or functioning at a very low-average level, when they are in fact n o rmal, leading to undesirable parental anxiety and over-referral for stimulation programs $s^{9,16,17,19-21}$. In o rder to avoid unnecessary worries and to counterbalance the disadvantages of under and overestimation, some authors have suggested using both ages for developmental assessment ${ }^{19,21}$.

During the last three decades, several standardized assessment tools, such as, Bayley Motor Scale of Infant Development ${ }^{12,17,21}$, Peabody Developmental Motor Scale ${ }^{7,13,14}$, Griffiths Motor Development Scales ${ }^{8,19}$, Gesell and Denver Developmental Scales ${ }^{15}$ have been used worldwide to assess at-risk pre te rminfant gross, fine motor, cognitive, social/emotional development for neurological disabilities. The Alberta Infant Motor Scale (AIMS) is a developmental assessment tool which was devised to evaluate infant gross motor skills, from birth to independent walking. AIMS provides an evaluative index (scores and percentile rank) which measures changes in motor perf o rmance over time, before and after intervention and compares them with the norm raw data measures ${ }^{22,23}$.

The purpose of the study was to assess the gross motor development of preterm infants, with low-risk for major motor neurological problems, during the first year of corrected age, using the AIMS in order to evaluate the need for correction of chronological age for the degree of prematurity, during this period.

\section{METHOD}

Fifty preterminborn infants, with low risk for neurological problems, were consecutively enrolled in a non-randomized way, and followed prospectively until independent walking, from June 2001 to November 2003. Data from the first visit after hospital discharge until 13 months of corrected age were used for statistical analysis. Infants were selected based on the mother willingness to participate in the study during the first follow-up visit, after hospital discharge. All infants were born at the Clinics Hospital of the University of São Paulo Medical School, from March 2001 to May 2002. The attending population comes predominantly from low social economic classes, with urban characteristics.

The Hospital Ethics Committee approved the study and a signed informed consent was obtained from all parents.

Infants with major intraventricular hemorrhages (grades III or IV of Papile ${ }^{24}$ ), moderate or severe neonatal hypoxicischemic encephalopathy ${ }^{25}$, cerebral malformations, genetic syndromes, visual or hearing deficits, or neonatal seizures we re excluded. Infants who developed neurological abnormalities (spasticity, reflex abnormalities, hypotonia, motor deficits) or seizures, during the follow-up period, were refe rred to neurological evaluation and, if it was confirmed, he was excluded from the study and assigned elsewhere to multidisciplinary intervention treatment.

All infants had neurological evaluations performed by one of the authors (JLDG) at the end of the follow-up period, to assure that none had a major neurological abnormality (motor delay, reflex abnorm a lity, muscle tone abnormality, focal neurological signs).

Infants were evaluated monthly according to AIMS 22 assessment tool criteria, through video tape recordings, either at home or at the hospital by one of the authors (APR) who had been trained for reliability for re se a rch use and had achieved $82 \%$ of agreement, in a pilot-study which took place before the data collection of the present study.

AIMS consists of 58 items organized into 4 postures: prone ( 21 items), supine ( 9 items), sitting (12 items), and standing (16 items). For each test item, the examiner must identify and score as observed /not observed according to a drawing of an infant in a specific position and three key descriptors (weight bearing, posture and antigravity movement).

During the assessment, the infants were laid undressed either on the examining table or on a firm mat. Younger infants, who did not assume or execute the positions independently, had to be placed. However neither facilitation, nor handling was allowed. In order to encourage and motivate the infants to move and explore the environment, verbal cues and toys were used. Each assessment lasted 30 to 50 minutes in order to the infant have enough time to show his motor performance in the four positions.

Gestational age (GA) was calculated based on the best obstetric estimate, in the following increasing order: date of the last menstrual period (when it was less than two weeks of the ultrasonographic evaluation), early ultrasonography performed with less than 20 weeks of GA, or New

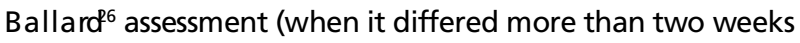
from the date of last menstrual period and early ultrasonography). Corrected age is calculated by subtracting the infant gestational age from 40 weeks and then subtracting this diffe rence from the infant chronological age at the time of testing.

The first three assessment interval periods according to ch ronological age were irregular (1-45 days; 46-95 days; $96-$ 105 days), but from the fourth assessment onwards, the interval periods were 30 days apart. The negative interval periods used for corrected age assessments represents those that took place before term, while the subsequent assessments kept the chronological age interval pattern. 
Statistical analysis - The sample size was calculated to demonstrate between-group diff e rences of 0.7 stan dard deviation, with a test power of $90 \%$ and a significance level of 0.05 . Mean scores were calculated monthly, considering both chronological and corrected ages. For each month, a $95 \%$ confidence interval $(95 \% \mathrm{Cl})$ for the mean score was calculated and comparisons were made between chronological and corrected data. If no overlapping was observed between the $\mathrm{Cl}$ mean scores corresponding to corrected and ch ronological ages, the diffe rences were considered as statistically significant $(p<0.05)$. An additional line is provided in the Figures representing an estimate of mean scores. For this purpose, a nonlinear model was adjusted to the observed mean score values. The fitting was considered adequate if the coefficient of determination $\left(r^{2}\right)$ was higher than 0.98 . The program SPSS, version 12.0 (Statistical Package for Social Science; Chicago ILL, USA) was used for statistical analysis.

\section{RESULTS}

Forty-three preterm infants without major neurological abnormality completed the study and all were able to walk unaided before 18 months of corrected age. Seven infants were excluded during the follow-up: two died, four developed cerebral palsy and one was lost. All infants were born with low birth-weight, 22 infants (51\%) weighed between 2499 and $1501 \mathrm{~g}, 16$ infants (37\%), between 1500 and $1001 \mathrm{~g}$, and 5 (12\%) weighed less than $1000 \mathrm{~g}$. Table 1 shows the general data of the study group.

The observed, estimated and confidence interv a I mean scores according to chronological and corre cted ages for each of the interval periods are shown respectively, in Tables 2 and 3.

Gross motor development scores were higher after age correction compared with those obtained when chronological ages were used, as shown in Fig 1 by the lack of overlapping between the two curves during the first twelve months. At thirteen months of age, we observed an overlapping of the confidence intervals suggesting that from that period onwards age correction for the degree of prematurity is no longer necessary (see also Tables 2 and 3).

Also, scores obtained when using chronological ages were lower in comparison with AIMS nomative data, as shown in Fig 2 (see also Tables 2 and 4). Furthemore, after age correction for the degree of prematurity our scores shifted upward and overlapped with AIMS normative ones as can be seen in Fig 3 .

Table 1. General characteristics of the study group.

\begin{tabular}{|c|c|}
\hline \multicolumn{2}{|l|}{ Variables } \\
\hline $\mathrm{N}$ & $43(100 \%)$ \\
\hline Gender & Male = $26(60 \%)$ \\
\hline Gestational age mean (range) & Mean $=32.8 \mathrm{w}(26-365 / 7)$ \\
\hline Birthweight mean (range) & Mean $=1668 \mathrm{~g}(670-2810)$ \\
\hline Intracranial hemorrhage & Grade I = $6(14 \%) ;$ Grade II = $3(7 \%)$ \\
\hline Small-for gestational-age & $17(40 \%)$ \\
\hline Oxygen therapy - open mask & $35(81 \%)$ \\
\hline Ventilator treatment & $12(28 \%)$ \\
\hline CPAP & $16(37 \%$ \\
\hline Length of hospitalization in days (range) & Mean $=31.37(3-97)$ \\
\hline \multirow[t]{5}{*}{ Mother's formal education } & Incomplete elementary grade: $13(30 \%)$ \\
\hline & Complete elementary grade: $4(10 \%)$ \\
\hline & Incomplete high school: 12 (28\%) \\
\hline & Complete high school: $13(30 \%)$ \\
\hline & Universitary level: $1(2 \%)$ \\
\hline \multirow[t]{2}{*}{ Race } & Nonwhite: 33 (77\%) \\
\hline & White: $10(23 \%)$ \\
\hline
\end{tabular}

CPAP, continuous positive airway pressure; $g$, grams; $N$, sample size; $w$, weeks. 
Table 2. Preterm infant mean scores according to chronological age.

\begin{tabular}{|c|c|c|c|c|c|}
\hline Period (m) & $\mathrm{N}$ & $\begin{array}{l}\text { Observed } \\
\text { mean }\end{array}$ & $\begin{array}{c}\text { Estimated } \\
\text { mean* }\end{array}$ & $\begin{array}{c}\text { Upper limit } \\
95 \% \mathrm{Cl}\end{array}$ & $\begin{array}{l}\text { Lower limit } \\
\quad 95 \% \mathrm{Cl}\end{array}$ \\
\hline$(0-45 d) 0.75$ & 20 & 2.7 & 2.94 & 3.18 & 2.22 \\
\hline$(46-95 d) 2.33$ & 38 & 5.08 & 5.03 & 5.73 & 4.42 \\
\hline$(96-105 d) 3.35$ & 21 & 7.24 & 7.03 & 8.32 & 6.16 \\
\hline$(106-135 d) 4$ & 31 & 8.81 & 8.63 & 9.59 & 8.02 \\
\hline$(136-165 d) 5$ & 33 & 11.67 & 11.68 & 12.74 & 10.59 \\
\hline$(166-195 d) 6$ & 35 & 15.06 & 15.49 & 16.48 & 13.62 \\
\hline$(196-225 d) 7$ & 30 & 20.53 & 20.01 & 22.51 & 18.55 \\
\hline$(226-255 d) 8$ & 36 & 24.64 & 25.12 & 27.01 & 22.26 \\
\hline$(256-285 d) 9$ & 31 & 30.97 & 30.52 & 34.29 & 27.64 \\
\hline$(286-315 d) 10$ & 28 & 34.86 & 35.89 & 37.92 & 31.79 \\
\hline$(316-345 d) 11$ & 24 & 42.29 & 40.88 & 45.78 & 38.80 \\
\hline$(346-375 d) 12$ & 19 & 44.58 & 45.26 & 48.56 & 40.60 \\
\hline (376-404 d) 13 & 24 & 48.96 & 48.90 & 51.85 & 46.07 \\
\hline
\end{tabular}

$\mathrm{Cl}$, confidence interval; $\mathrm{d}$, day (s); $\mathrm{m}$, months; $\mathrm{N}$, sample size; *Adjusted mean scores by non-linear model $(\mathrm{r}=0.99)$

Table 3. Preterm infant mean scores according to corrected age.

\begin{tabular}{|c|c|c|c|c|c|}
\hline Period (m) & $\mathrm{N}$ & $\begin{array}{l}\text { Observed } \\
\text { mean }\end{array}$ & $\begin{array}{c}\text { Estimated } \\
\text { mean* }\end{array}$ & $\begin{array}{c}\text { Upper limit } \\
95 \% \mathrm{Cl}\end{array}$ & $\begin{array}{l}\text { Lower limit } \\
\quad 95 \% \mathrm{Cl}\end{array}$ \\
\hline$(<376 / 7$ pcw $)-0.75$ & 15 & 2.07 & 2.78 & 2.63 & 1.49 \\
\hline$(38-40 \mathrm{pcw})-0.125$ & 20 & 3.5 & 3.50 & 4.15 & 2.85 \\
\hline$(1-45 d) 0.75$ & 36 & 5.72 & 4.80 & 6.41 & 5.04 \\
\hline$(46-95 d) 2.33$ & 41 & 7.93 & 8.29 & 8.48 & 7.37 \\
\hline$(96-105 d) 3.35$ & 24 & 12 & 11.52 & 13.09 & 10.91 \\
\hline$(106-135 d) 4$ & 32 & 14.3 & 14.04 & 15.39 & 13.23 \\
\hline$(136-165 d) 5$ & 31 & 18.77 & 18.58 & 20.35 & 17.19 \\
\hline$(166-195 d) 6$ & 34 & 23.12 & 23.83 & 24.72 & 21.51 \\
\hline$(196-225 d) 7$ & 32 & 28.91 & 29.49 & 31.39 & 26.42 \\
\hline$(226-255 d) 8$ & 29 & 35.27 & 35.14 & 38.48 & 32.07 \\
\hline$(256-285 d) 9$ & 28 & 40.82 & 40.41 & 43.87 & 37.77 \\
\hline$(286-315 d) 10$ & 24 & 44.83 & 44.98 & 48.30 & 41.36 \\
\hline$(316-345 d) 11$ & 15 & 49.53 & 48.73 & 51.84 & 47.22 \\
\hline$(346-375$ d) 12 & 16 & 51.62 & 51.65 & 53.73 & 49.51 \\
\hline$(376-404 d) 13$ & 14 & 53.28 & 53.84 & 56.86 & 49.70 \\
\hline
\end{tabular}

$\mathrm{Cl}$, confidence interval; $d$, days; $\mathrm{m}$, months; $\mathrm{N}$, sample size; pcw, pos-conceptual week *Adjusted mean scores by non-linear model $(r=0.99)$ 
Table 4. AIMS mean scores.

\begin{tabular}{|c|c|c|c|c|}
\hline Período (m) & $\mathrm{N}$ & $\begin{array}{c}\text { Estimated } \\
\text { mean* }\end{array}$ & $\begin{array}{c}\text { Upper limit } \\
95 \% \mathrm{Cl}\end{array}$ & $\begin{array}{c}\text { Lower limit } \\
95 \% \mathrm{Cl}\end{array}$ \\
\hline$(0-1) 0.5$ & 22 & 4.61 & 4.89 & 4.10 \\
\hline$(1-2) 1.5$ & 56 & 6.63 & 7.84 & 6.76 \\
\hline (2-3) 2.5 & 118 & 9.37 & 10.47 & 9.12 \\
\hline (3-4) 3.5 & 90 & 12.96 & 13.51 & 11.68 \\
\hline$(4-5) 4.5$ & 122 & 17.45 & 19.05 & 16.75 \\
\hline (5-6) 5.5 & 189 & 22.72 & 24.51 & 21.88 \\
\hline (6-7) 6.5 & 225 & 28.50 & 29.81 & 26.79 \\
\hline (7-8) 7.5 & 222 & 34.36 & 34.18 & 30.41 \\
\hline$(8-9) 8.5$ & 220 & 39.86 & 42.19 & 37.40 \\
\hline$(9-10) 9.5$ & 189 & 44.65 & 47.56 & 43.44 \\
\hline$(10-11) 10.5$ & 155 & 48.56 & 50.93 & 47.67 \\
\hline$(11-12) 11.5$ & 155 & 51.59 & 53.26 & 49.34 \\
\hline$(12-13) 12.5$ & 124 & 53.84 & 55.85 & 53.35 \\
\hline (13-14) 13.5 & 86 & 55.47 & 56.99 & 54.21 \\
\hline$(14-15) 14.5$ & 61 & 56.62 & 57.46 & 56.34 \\
\hline (15-16) 15.5 & 40 & 57.42 & 57.92 & 57.67 \\
\hline
\end{tabular}

m, months; $N$, sample size; *Mean was generated from non-linear model of AIMS data (Piper and Darrah. 1994).

\section{DISCUSSION}

There is much debate over the use of either corrected or chronological age scores to evaluate infant developmental level, most of them dealing with problems of reducing measurement errors. Our results showed that, when using chronological age, motor development of preterm infants with low-risk for $n$ e u rological disorders is underestimated during the first year of life, according to AIMS, leading to falsenegative diagnostic of motor delay. The preterm infant gross motor development seems to maturate according to conceptional rather than chronological age. There fo re our data suggest, in accordance with other studies $7,8,12-16,20,27$, that correction of chronological age for the degree of prematurity is the best way to effectively evaluate preterm infants, as far as gross motor development is concerned.

Although some developmental assessment tools favor chronological age correction ${ }^{28,29}$, there are still controversies regarding the best correction method (full or partial) and its implications for intervention eligibility. Some ${ }^{28}$ leave to the examiner the decision to administer the item based on either corrected or chronological age and to compare the normative sample to derive the standard scores. Therefore, the same child may have diff e rent score outcome depending on the examiner approach, ranging from significant delay to normal ${ }^{30}$.

We observed that our infants had dronological age mean scores lower than corrected age scores during the first year. Although the assessment tools used in other studies included only a few fine motor items as part of the developmental assessment and used somewhat diff e rent measures of development, they a gree with our results $13,14,16,17,21$. Mancini et al. ${ }^{27}$ found that preterminfants, without neurologic disorders and with age correction, showed a similar motor development at 8 and 12 months, when using AIMS and Pediatric Evaluation of Disability Inventory (PEDI), respectively, corroborating our results.

Lems et al. ${ }^{17}$ observed that pretermchronological scores were statistically lower than full-term and corrected age scores only during the second half of the first year, while Siege ${ }^{21}$ reported that chronological age scores were significantly lower for very low birth-weight infants, at two years of age, compare d 


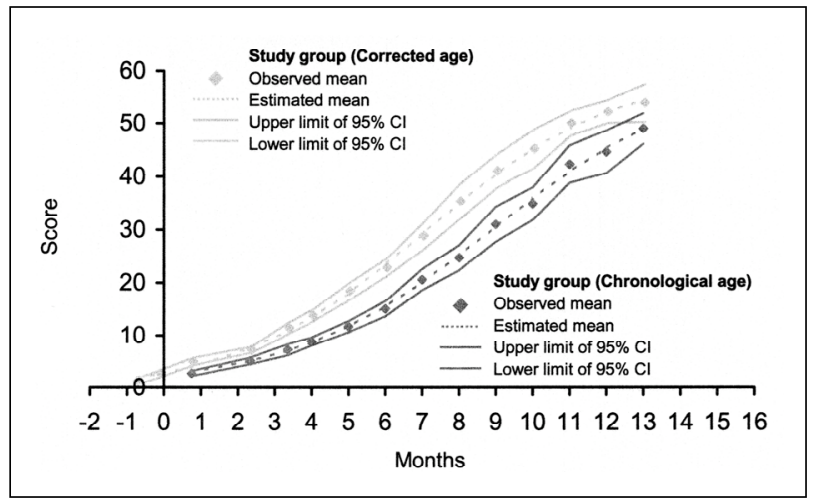

Fig 1. Confidence intervals $(95 \% \mathrm{Cl})$ for the mean scores of gross motor development in preterminfants. The dark grey lines and the light grey lines correspond to the chronological and cor rected ages respectively. The dotted lines represent the esti mate of mean scores obtained by nonlinear fitting: $y=a / 1+(b$ * $\exp (-c x))$.

with full-term infants. Others ${ }^{13,14}$ reported that when ch ronological age was used, preterm infant chro n ological and corrected mean scores were significantly lower than full-term.

We found that full age correction should be used to assess preterm motor development throughout the first year of corrected age. Siegel ${ }^{21}$ used full correction only in the early months, whereas Lems et al. ${ }^{17}$ used it in the first 6 months of life and then partial correction, up to one year. When assessing preterm motor development by Peabody Developmental Motor Scale, age correction should be used at least up to 18 months of age ${ }^{13}$, but in an earlier study, the same author ${ }^{14}$ reported the need for correcting up to one year. All these studies have justified the correction procedure due to the fact that it could increase the specificity of the assessment tool for identifying preterm infants with real motor delay 13,14,17,21.

Although we were not able to verify whether partial age correction would be more appropriate to assess motor development during the first year of corrected age, we observed a tendency of the chronological age curve to reach the corrected age curve during the last months of the first year of life, a fact that would suggest that partial correction would be possible during this age period. However, further studies should be done in order to investigate when and how partial correction should be applied, and if this procedure depends only on the degree of prematurity.

The use of full correction, partial, or no correction is based on two theoretical points of view on in-

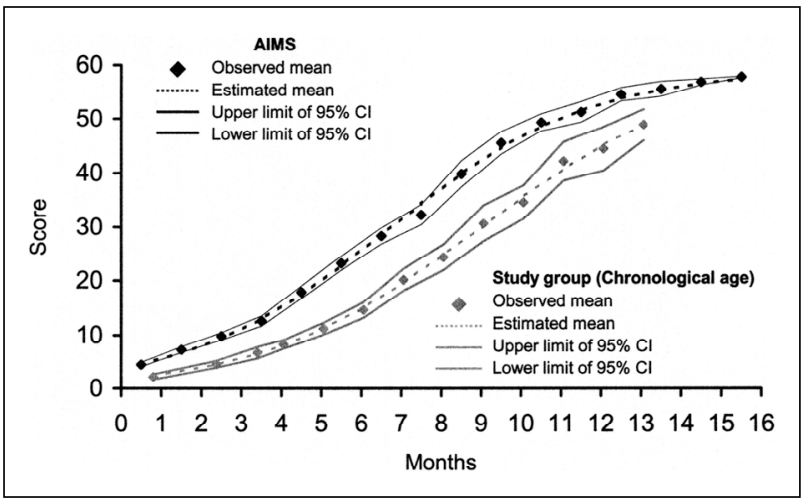

Fig 2. Confidence intervals $(95 \% \mathrm{Cl})$ for the mean scores of gross motor development in preterminfants. The dark grey lines re $p$ resent the chronological ages observed in this study. AIMS normative data are shown in black lines for comparison.

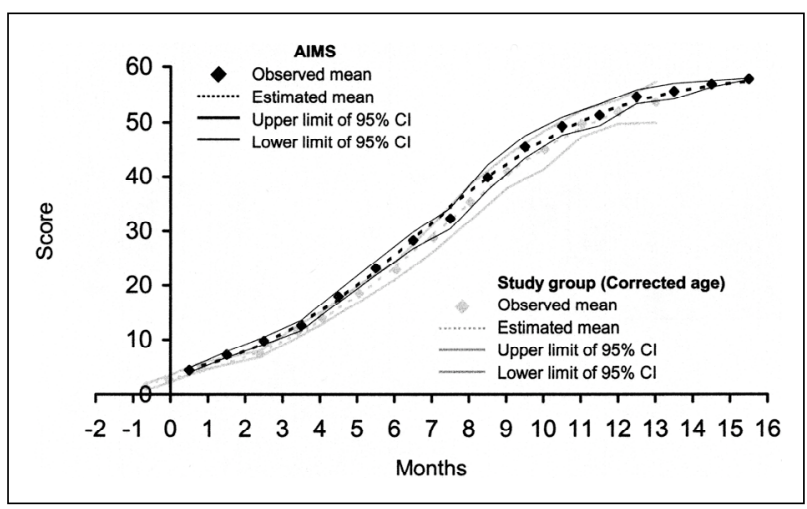

Fig 3. Confidence intervals $(95 \% \mathrm{Cl})$ for the mean scores of gross motor development in preterminfants. The light grey lines rep resent the corrected ages observed in this study. AIMS nor mative data are shown in black lines as reference. The similar ity of scores corresponding to the corrected ages in our study is suggested by the overlapping of confidence intervals.

fant maturation. The biological perspective states that development is determined by the maturation of central nervous system, independently of environmental influences ${ }^{31}$. Correction for the degree of prematurity was devised to decrease the transient delay in preterminfant development until they catch up with their full-term peers. The environmental perspective favors using chronological age, as it places higher importance on the role of external factors in the development of preterminfants ${ }^{30,32}$ while partial correction intends to counter-balance the full correction and no correction approaches. Regardless of the theo retical framework it is unclear to what extent medical factors have negative effects beyond gestational age or to what extent environmental factors accelerate or inhibit the developmental functioning of preterm infants. 
Not only have the studies ${ }^{12,19-21}$ differed as to when overestimation has occurred, but they have also reached conflicting conclusions re $g$ a rding the choice of whether or not to use both ages. Whereas some studies ${ }^{12,20}$ suggested using only corrected age, as it can be a more sensitive index of developmental delay, others ${ }^{19,21}$ supported using both ages during the first year. The decrease in the sensitivity in the assessment tool when using corrected age, and the advantages of increasing sensitivity to correctly identify the neurological abnormal preterm infants were the most often cited arguments.

The main clinical implication of correction of chronological age for the degree of prematurity is that this could postpone the diagnosis of a developmental delay, as it may lead to overestimation of the infant development, whereas when no correction is used this could underestimate it, particularly, in extremely preterm infants. On the other hand, overdiagnosis of a developmental delay leads to unnecessary re $f$ e rrals to therapeutic interventions, which in turn, creates unwarranted anxiety for the parents ${ }^{19,21}$.

We observed that there was an overlap of chronological and corrected age mean scores confidence intenals at thirteen month of age (Fig 1), showing that, from this age onwards, correction for the degree of prematurity is no longer necessary. We do not know whether this pattern is maintained further on, because we did not study the motor developmental behavior beyond this age. All infants had been assessed by a pediatric neurologist after walk attainment to exclude infants with major neurological signs of cerebral palsy. Several studies have shown that many pretermchildren without cerebral palsy may show minor neurological signs and /or perceptualmotor difficulties at school age ${ }^{33,34}$. However, further investigations should be done to investigate whether the infants that have performed different from the average, may be predictive to minor neurological signs.

A neurodevelopmental assessment tool should be able to discriminate correctively infants with neuromotor delay from those with normal development. Our results suggest that, when using AIMS, scores should be corrected for the degree of prematurity to more accurately identify infants with real delay, which is in agreement with AIMS criteria ${ }^{22}$. This is due to the fact that the scores of pretermwith real motor delay will fall beyond the lower limit of the percentile-rank curve.

Several infants missed one or more assessments during the study period for different reasons. Monthly assessments, at the outpatient clinic, were jeopa rdized due to the fact that our children came fro $m$ low social economic background, lived in the periphery of the city, and were difficult to get in touch by phone. Additionally, they were infants without major ne u rological abnormalities, a fact against a natural motivation for a periodic neurodevelopmental assessment. However, we believe that our results were not likely to be affected as the assessments were frequent th roughout the study period. Most of cohort studies that deal with pre te rmfollow-up assessments in the first two years of age do not analyze data monthly ${ }^{7}$ 9,12-17,19-21.

Children with cerebral palsy were excluded during follow-up, because the objective of the study was to study the motor development of preterm with low-risk for neurological disorders. The inclusion of these infants would have lowered the observed mean scores and underestimated motor development of the whole sample. Besides, AIMS is a scale that was not devised to monitor motor development of infants with neurological abnormalities ${ }^{22}$.

We conclude that full correction of chronological age for the degree of prematurity should be used when assessing preterminfants gross motor development during the first year of corrected age.

\section{REFERENCES}

1. Hack M, Fanaroff AA. Outcomes of children extremely low-birth-weight and gestational age in the 1990's. Early Hum Dev 1999;53:193-218.

2. Han TR, Bang MS, Lim JY, Yoon BH, Kim IO. Risk factors of cerebral palsy in preterm infants. Am J Phys Med Rehabil 2002;81:297-303.

3. Ment LR, Vohr B, Allan W, et al. Change in cognitive function over time in very low-birth- weight infants. JAMA 2003;289:705-711.

4. Sweeney KJ, Gutierrez T. Musculoskeletal implications of preterm infant positioning in the NICU. J Perinat Neonat Nurs 2002;16:58-70.

5. Monterosso L, Kristjanson LJ, Cole J, Evans SF. Effect of postural supports on neuromotor function in very preterm infants to term equivalent age. J Paediatr Child Health 2003;39:197-205.

6. Vaivre-Douret L, Ennouri K, Jrad I, Garrec C, Papiernik E. Effect of positioning on the incidence of abnormalities of muscle tone in lowrisk, preterm infants. Eur J Paediatr Neurol 2004;8:21-34.

7. Piper MC, Byrne PJ, Darrah J, Watt MJ. Gross and fine motor development of preterm infants at eight and 12 months of age. Dev Med Child Neurol 1989;31:591-597.

8. Stjernqvist K, Svenningsen NW. Extremely low-birth-weight infants less than $901 \mathrm{~g}$ : development and behaviour after 4 years of life. Acta Paediatr 1995;84:500-506.

9. Thun-Hohenstein L, Largo RH, Molinari L, Kundu S, Duc G. Early fine motor and adaptative development in high-risk appropriate for gestational age preterm and healthy term children. Eur J Pediatr 1991;150:562-569.

10. Palmer PG, Dubowitz LMS, Verghote M, Dubowitz V. Neurological an neurobehavioral differences between preterm infants at term and fullterm newborn infants. Neuropediatrics 1982;13:183-189.

11. Paludetto R, Rinaldi P, Mansi G, Andolfi M, Del Giundice G. Early behavioural development of preterm infants. Dev Med Child Neurol 1984;26:347-352.

12. Hunt JV, Rhodes L. Mental development of preterm infants during the first year. Child Dev 1977;48:204-210. 
13. Palisano RJ. Use of chronological and adjusted ages to compare motor development of healthy preterm and fullterm infants. Dev Med Child Neurol 1986;28:180-187.

14. Palisano RJ, Short MA, Nelson DL. Chronological vs. adjusted age in assessing motor development of healthy twelve-month-old premature and fullterm infants. Phys Occup Ther Pediatr 1985;5:1-16.

15. Parmelee AH, Schulte FJ. Developmental testing of pre-term and smallfor-date infants. Pediatrics 1970;45:21-28.

16. Allen MC, Alexander GR. Gross motor milestones in preterm infants: correction for degree of prematurity. J Pediatr 1990;116:955-959.

17. Lems W, Hopkins B, Samson JF. Mental and motor development in preterm infants: the issue of corrected age. Early Hum Dev 1993;34:113123.

18. Blasco PA. Preterm birth: to correct or not correct. Dev Med Child Neurol 1989;31:816-826.

19. Miller G, Dubowitz LMS, Palmer P. Follow-up of preterm infants: is correction of the developmental quotient for prematurity helpful? Early Hum Dev 1984;9:137-144.

20. Ouden LD, Rijken M, Brand R, Verloove-Vanhorick SP, Ruys JH. Is it correct to correct? Developmental milestones in 555 "normal" preterm infants compared with term infants. J Pediatr 1991;118:399-404.

21. Siegel LS. Correction for prematurity and its consequences for the assessment of the very low birth weight infant. Child Dev 1983;54:11761188.

22. Piper MC, Darrah J. Motor assessment of the developing infant. Philadelphia: WB Saunders, 1994.

23. Piper MC, Pinnell LE, Darrah J, Maguire T, Byrne PJ. Construction and validation of the Alberta Infant Motor Scale (AIMS). Can J Pub Health 1992;83(Suppl):S46-S50.

24. Papile LA, Burstein J, Burstein R, Koffler H. Incidence and evolution of subependymal and intraventricular hemorrhage: a study of infants with birth-weights less than 1.500g. J Pediatr 1978;92:529-534.

25. Sarnat HB, Sarnat MS. Neonatal encephalopathy following fetal distress: a clinical and eletroencephalographic study. Arch Neurol 1976;33:696-705.

26. Ballard JL, Khoury JC, Wedig K, Wang L, Eliers-Walsman BL. New Ballard Score: expanded to include extremely premature infants. J Pediatr 1991;119:417-423.

27. Mancini MC, Teixeira S, Araújo LG, et al. Estudo de desenvolvimento da função motora aos 8 e 12 meses de idade em crianças nascidas prétermo e a termo. Arq Neuropsiquiatr 2002;60:974-980.

28. FrankenburgWK, Dodds J, A rcher P, et al. Denver II screening manual. Denver, CO: Denver Developmental Materials, 1990.

29. Bayley N. Bayley scales of infant development. $2^{\text {nd }}$ edition. San Antonio, TX: Psychological Corporation, 1993.

30. Wilson SL, Cradock MM. Review: accounting for prematurity in developmental assessment and the use of age-adjusted scores. J Pediatr Psychol 2004;29:641-649.

31. Gesell A, Amatruda CS. Developmental Diagnosis. New York: Hoeber, 1947.

32. Zahr LK. Predictors of development in premature infants from lowincome families: African Americans and Hispanics. J Perinatol 1999;19:284-289.

33. Jongmans M, Merucuri E, de Vries L, Dubowitz L, Henderson SE. Minor neu rological signs and perceptual-motor difficulties in prematurely born children. Arch Dis Child 1997;76:9-14.

34. Walther FJ, den Ouden LA, Verloove-Vanhorick SP. Looking back in time: outcome of national cohort of very preterm infants born in The Netherlands in 1983. Early Hum Dev 2000;59:175-191. 